\title{
Prediction of Wear Resistance of Ultrasonic Electrodeposited Ni- SiC Nanocoatings using BP-NN Model
}

\author{
Hui Wang ${ }^{1}$, Weipeng $\mathrm{Yu}^{1}$, Haijun Liu ${ }^{1,}$, Qiang $\mathrm{Li}^{2}$, Fafeng $\mathrm{Xia}^{2}$, Chunyang $\mathrm{Ma}^{2}$ \\ ${ }^{1}$ College of Engineering and Technology, Jiyang College of Zhejiang Agriculture \& Forestry University, \\ Zhuji, 311800, China; \\ ${ }^{2}$ College of Mechanical Science and Engineering, Northeast Petroleum University, Daqing 163318, \\ China \\ *E-mail: chunyangandma@163.com,20180050@zafu.edu.cn (H. Liu)
}

doi: $10.20964 / 2021.04 .29$

Received: 15 November 2020 / Accepted: 26 January 2021 / Published: 28 February 2021

\begin{abstract}
This paper adopts neural network technology to construct a BP-NN (Back-propagation neural network) model with $3 \times 8 \times 1$ structure, and the model was used to predict the wear resistance of ultrasonically electrodeposited Ni-SiC nanocoating. The impact of plating parameters on composition and microstructure of the Ni-SiC nanocoatings were investigated by scanning electron microscopy (SEM), atomic force microscopy (AFM), and X-ray diffraction (XRD) and wear testing. The results indicated that when the number of hidden layers and neurons of the BP-NN model are 1 and 8 , respectively, and the root mean square error of the BP-NN model was minimal with a value of $1.24 \%$. The prediction value of the BP-NN model was not much different from the experimental value, and the maximum error obtained was $1.51 \%$. When the concentration of $\mathrm{SiC}$ particles was taken as $8 \mathrm{~g} / \mathrm{L}$, current density was maintained at $2 \mathrm{~A} / \mathrm{dm}^{2}$, and the temperature was kept at $40^{\circ} \mathrm{C}$, the $\mathrm{SiC}$ particles were uniformly distributed in the Ni-SiC nanocoating, and the nickel grains of the coating were significantly refined, as indicated by the diffraction peaks of the nickel grains which became wider and shorter.
\end{abstract}

Keywords: Ni-SiC nanocoating; BP-NN model; microstructure; wear; prediction

\section{FULL TEXT}

(C) 2021 The Authors. Published by ESG (www.electrochemsci.org). This article is an open access article distributed under the terms and conditions of the Creative Commons Attribution license (http://creativecommons.org/licenses/by/4.0/). 